1

2

3

4

5

6

7

8

9

\section{Oxidized carbon nanofibers supporting PtRu nanoparticles for direct methanol fuel cells}

\author{
10 * Corresponding author: María Jesús Lázaro, Instituto de Carboquímica, CSIC, Miguel \\ 11 Luesma Castán 4, 50018, Zaragoza, Spain. Fax: +34 976733318; Tel: +34 976733977;

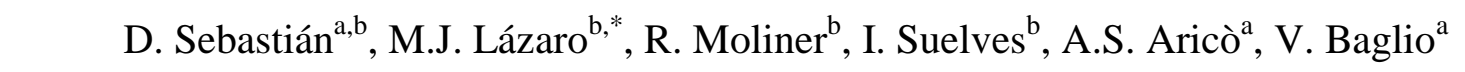 \\ a Istituto di Tecnologie Avanzate per l'Energia "Nicola Giordano", CNR, \\ Via Salita S. Lucia sopra Contesse 5, 98126, Messina, Italy. \\ ${ }^{b}$ Instituto de Carboquímica, CSIC, \\ C/Miguel Luesma Castán 4, 50018, Zaragoza, Spain. \\ E-mail:mlazaro@icb.csic.es
}

9 


\section{Abstract}

Oxidized carbon nanofibers (CNFs) have been investigated as supports for PtRu nanoparticles. Two distinct CNFs characterized by different surface area and crystallinity have been considered and treated with nitric acid and a mixture of sulfuric and nitric acids to introduce oxygen functionalities. The oxidized CNFs have been then physico-chemically characterized and used for the preparation of PtRu/CNF catalysts by a modified microemulsion procedure. PtRu nanoparticles of ca. $2 \mathrm{~nm}$ size were obtained despite the relatively low surface area of CNFs (90-180 $\left.\mathrm{m}^{2} \mathrm{~g}^{-1}\right)$. A good particle distribution on the supports has been obtained, as confirmed by TEM micrographs and by the high values of electrochemically active surface areas (up to $200 \mathrm{~m}^{2} \mathrm{~g}^{-1}$ ). Catalysts based on oxidized carbon nanofibers present a significant increase of activity toward the electro-oxidation of methanol. The effect of oxidation treatments is not independent of the CNF properties, which must be considered for a convenient support optimization. Nevertheless, the optimum support is obtained when balancing three parameters: a sufficient electrochemical surface area, an improved metal-support interaction due to the effect of oxygen functionalities, and better methanol diffusion through the catalyst pores due to the wettability of oxidized CNFs.

Keywords: carbon nanofibers, oxidation, functionalization, platinum-ruthenium, methanol oxidation 


\section{Introduction}

Direct alcohol fuel cells (DAFCs) represent a valid alternative to Li-ion batteries for small portable electronic devices and auxiliary power units, due to the high energy density of alcohols, lightweight, compactness, simplicity as well as easy and fast recharging [1-7]. The main drawbacks toward the commercialization of DAFC technologies are still the high cost and the unsatisfactory component lifetime, which are derived mainly from the use of noble metal catalysts and perfluorosulfonated polymer electrolyte membranes [8-11]. Regarding the use of noble metals, it is necessary to develop catalytic structures that maximize the utilization of platinum and platinum group metals for an adequate fuel cell performance. One of the most promising strategies is the use of advanced supports that stabilize metal nanoparticles, allow good diffusion paths for reactants and products, offer a high electrical conductivity and resist corrosion phenomena in the electrode environment [12-19].

Carbon supports still present the best compromise of properties to fulfill fuel cell requirements in terms of electrocatalytic activity. With the scope of improving the distribution of platinum-based nanoparticles on the surface of carbon supports, a plausible strategy is to create surface functionalities based on oxygen groups. Acid treatment is effective to introduce oxygen atoms on the carbon surface being part of functionalities such as carboxylic acids, anhydrides, lactones, hydroxyls or carbonyls $[20,21]$. The functionalities may act as anchoring sites for the metal catalysts and eventually aid in their adsorption on the carbon surface by numerous mechanisms, which include adsorption, ion-exchange or coordination reactions [22, 23]. Moreover, the presence of oxygen-carrying polar functional groups enhances the surface hydrophilicity, which aids the diffusion of methanol fuel (aqueous solution) to achieve all the available catalytic active sites.

There are not yet clear indications in the literature about the real effect of oxygen groups on the electrochemical behavior of platinum-ruthenium catalysts. Carmo et al. [24, 25] found that oxidizing the benchmark support (carbon black Vulcan $\mathrm{XC72R}$ ), with either nitric or sulfuric acids, results in a significant improvement of direct methanol fuel cell (DMFC) performance. They attributed the enhanced catalytic activity to a better distribution of PtRu nanoparticles on the surface, and/or the better wettability of the support, and/or a higher resistance to $\mathrm{CO}$ poisoning. Salgado et al. 
1 [26] found that the electrochemically active surface area decreases from 70 to $54 \mathrm{~m}^{2} \mathrm{~g}^{-1}$

2 when using functionalized Vulcan, evidencing a detrimental effect on Pt dispersion, but

3 still obtaining a significant improvement of DMFC performance. According to this, the

4 positive effect of the oxidized carbon support is not attributed to a better nanoparticle

5 distribution on the surface. The authors explain such enhancement in terms of surface

6 polarity caused by the contribution of oxygen groups, leading to 2.5 times higher

7 performance despite the worse noble metal surface area.

Not only conventional carbon blacks but also the functionalization of novel carbon structures has been investigated very recently. Figueiredo et al. reviewed the synthesis and functionalization of high surface area carbon xerogels (CXGs) [27]. They individuated the effect of different oxygen groups and rationalized the improvement of activity of PtRu catalysts as the result of two contrary effects: the presence of carboxylic and anhydride groups, which influences the stability and oxidation state of active metals; and the decrease of conductivity of the support influenced by the presence of surface oxygen groups. Alegre et al. also observed a significant variation of the oxidation state of $\mathrm{Pt}$ and $\mathrm{Ru}$ with the presence of carboxylic and lactone groups on CXGs [28]. However, although a significant improvement of the intrinsic activity of the catalysts is obtained with surface oxygen groups, the detrimental effect on nanoparticle dispersion and distribution, caused by a preferential metal growth on surface defects, results in no significant advantage for functionalized CXGs compared to untreated ones $[28,29]$. All these works highlight the difficulties to individuate the effect of using oxidized carbon supports due to the scattering of data caused by different support properties and distinct catalyst preparation methods. To this purpose, Gómez de la Fuente et al. [30, 31] studied the combined effect of the functionalization of carbon black and PtRu synthesis methodologies. They concluded that the influence of both oxygen groups and synthesis procedures on the metal-support interaction and catalyst morphology are of key importance to maximize the PtRu utilization. In this regard, oxygen functionalities may play an important role in stabilizing Pt-based nanoparticles and influencing the electrochemical behavior of the catalyst.

The objective of the present work is to determine whether the functionalization of highly graphitic carbon nanofibers (CNFs) produces a significant enhancement of PtRu catalyst performance in DMFC. These CNFs possess a relatively low surface area 
$1 \quad\left(100-150 \mathrm{~m}^{2} \mathrm{~g}^{-1}\right)$, which hinders the dispersion of the active phase on the surface. High 2 metal concentrations $(\geq 50 \mathrm{wt} \%$ ) on carbon are commonly used to minimize the 3 electrode thickness and maximize fuel cell performance [1]. However, efforts are 4 currently focused on the reduction of metal loading in the electrodes $\left(\leq 1 \mathrm{mg} \mathrm{cm}^{-2}\right)$ for 5 cost-effective devices. This allows the electrode fabrication based on catalysts with low 6 metal concentration on the carbon support in order to obtain a high surface area. In the 7 present work, a microemulsion route was used to prepare high surface area $20 \mathrm{wt} \%$ 8 PtRu nanoparticles supported on different CNFs in order to carry out an independent 9 cross-analysis of support features and catalytic activity. 


\section{Experimental details}

\subsection{Preparation and oxidation of carbon nanofibers}

Carbon nanofibers were prepared at $600^{\circ} \mathrm{C}$ (named CNF600) and $700^{\circ} \mathrm{C}$ (named CNF700) by the catalytic decomposition of methane on a nickel-based catalyst, according to previous works $[32,33]$. Two temperature values were selected to provide CNFs with two different diameters (28 nm for CNF600 and $54 \mathrm{~nm}$ for CNF700 [32]) and graphitization degrees, and consequently favor either the surface area (at $600^{\circ} \mathrm{C}$ ) or the crystallinity (at $700^{\circ} \mathrm{C}$ ). Both CNFs were functionalized by oxidation treatments, refluxing with concentrated acid solutions of $\mathrm{HNO}_{3}$ or $\mathrm{HNO}_{3}: \mathrm{H}_{2} \mathrm{SO}_{4}(1: 1 \mathrm{v} / \mathrm{v})$. In these solutions the nitronium ion, $\mathrm{NO}_{2}{ }^{+}$, attacks the carbonaceous surface, which is presumably the first step in the introduction of oxygen surface groups. The addition of sulfuric acid increases the oxidation extent. With the purpose of maintaining a similar oxidation degree with both acid compositions, and based on previous studies [34, 35], boiling temperature $\left(110^{\circ} \mathrm{C}\right)$ was used for the $\mathrm{HNO}_{3}$ treatment and room temperature for the $\mathrm{HNO}_{3}: \mathrm{H}_{2} \mathrm{SO}_{4}$ treatment. The duration of the experiments was 30 minutes in all cases. The acid concentrations employed were $65 \mathrm{wt} \%$ for nitric acid and $96 \mathrm{wt} \%$ for sulfuric acid in water, as purchased from Panreac. After oxidation, samples were thoroughly washed with deionized water until neutral $\mathrm{pH}$ and subsequently dried at 100 ${ }^{\circ} \mathrm{C}$ overnight.

\subsection{Deposition of PtRu nanoparticles on oxidized carbon nanofibers}

The scope of the synthesis of PtRu catalysts was to obtain similar particle sizes independently of support surface area and surface chemistry. For this reason, a microemulsion route was employed [36-38], in which the encapsulation of metal precursors in reverse micelles limits the metal crystallites growth to a few nanometers. Briefly, it consists of preparing a microemulsion composed by $16.5 \%$ surfactant (polyethylene glycol dodecyl ether, Brij ${ }^{\circledR} 30$, Sigma-Aldrich), $3.9 \%$ aqueous solution containing the metal precursors $\left(0.05 \mathrm{M} \mathrm{H}_{2} \mathrm{PtCl}_{6}\right.$ and $\left.0.05 \mathrm{M} \mathrm{RuCl}_{3}\right)$ and n-heptane as the hydrophobic phase. Subsequently, the appropriate amount of carbon support is dispersed in the microemulsion under sonication for at least one hour in appropriate amount for a metal concentration in the catalyst of $20 \mathrm{wt} \%$. The reduction step involves the slow addition of sodium borohydride in excess at room temperature and under 
1 vigorous stirring for 16 hours. Finally the catalyst is thoroughly washed with ethanol and water to remove the microemulsion components used during the synthesis, and dried overnight at $60^{\circ} \mathrm{C}$.

\subsection{Physico-chemical characterization}

Textural properties of carbon supports such as the specific surface area and the pore volume were determined from nitrogen adsorption-desorption isotherms, measured at $-196{ }^{\circ} \mathrm{C}$ using a Micromeritics ASAP 2020. Total surface area and pore volume were calculated using the Brunauer-Emmet-Teller (BET) equation and the single point method, respectively.

The quantitative and qualitative determination of the oxygen surface groups was carried out by means of temperature programmed desorption (TPD) experiments. Typically, $300 \mathrm{mg}$ of carbon material was placed in a U-shaped quartz reactor. The temperature was increased at a rate of $10{ }^{\circ} \mathrm{C} \mathrm{min}^{-1}$ from room temperature up to $1050{ }^{\circ} \mathrm{C}$ under a helium flow of $30 \mathrm{~cm}^{3} \mathrm{~min}^{-1}$. The amounts of $\mathrm{CO}$ and $\mathrm{CO}_{2}$ desorbed from the carbon samples were analyzed by gas chromatography. The distribution of oxygen functional groups was estimated from the deconvolution of TPD curves into the different contributions by Gaussian functions and numerical routines. According to previous publications [21, 34, 39], in order to determine the relative amount of each surface group, some assumptions were considered for the deconvolution of $\mathrm{CO}_{2}$ and $\mathrm{CO}$ curves: $\mathrm{CO}_{2}$ profile is decomposed into three contributions corresponding to carboxylic acids, anhydrides and lactones (in increasing order of desorption temperature), whereas, $\mathrm{CO}$ profile is decomposed into three contributions corresponding to anhydrides, hydroxyls and carbonyls. An anhydride group decomposes releasing $1 \mathrm{~mol}$ of CO and 1 mol of $\mathrm{CO}_{2}$, thus the corresponding peak must have the same shape and magnitude in the deconvolution of both $\mathrm{CO}$ and $\mathrm{CO}_{2}$ curves.

The crystallinity of platinum-ruthenium crystallites and carbon was studied by X-Ray Diffraction. XRD patterns were performed using a Bruker AXS D8 Advance diffractometer, using $\mathrm{Cu}-\mathrm{K} \alpha$ radiation. Crystallite sizes were calculated from the Scherrer's equation applied to the (220) peak for platinum related reflections. 
High-resolution transmission electron microscope (HRTEM) micrographs were obtained using a JEOL-2000 FXII microscope at $200 \mathrm{kV}$ and with a spatial resolution of $0.28 \mathrm{~nm}$. To obtain the micrographs, the catalyst samples were finely grinded and ultrasonically dispersed in ethanol. A drop of the resultant dispersion was deposited and dried onto a standard copper grid coated with Lacey carbon.

Energy dispersive X-ray (EDX) analyses and thermogravimetric analyses (TGA) in air were performed to quantify the metal loading and composition of the PtRu/CNF electrocatalysts. EDX measurements were also used to determine the Pt:Ru atomic ratio. An EDX analyzer Röntec XFlash $\mathrm{Si}(\mathrm{Li})$ coupled to a Hitachi S-3400N scanning electron microscope (SEM) was used for that purpose. For TGA experiments in air, a Setaram Setsys Evolution thermogravimetric analyzer was used at atmospheric pressure, and the temperature was varied from room temperature to $950^{\circ} \mathrm{C}$ with a constant rate of $5^{\circ} \mathrm{C} \mathrm{min}^{-1}$.

\subsection{Electro-chemical characterization}

$\mathrm{PtRu} / \mathrm{CNF}$ electrocatalysts were characterized in half-cell. Half-cell set-up consisted in a three-electrode assembly and an Autolab Potentiostat-Galvanostat. A large area pyrolitic graphite rod served as the counter electrode and a reversible hydrogen electrode (RHE) system was used as the reference electrode. The working electrodes were composed of the electrocatalysts deposited as a thin layer over a pyrolitic graphite disk $\left(0.38 \mathrm{~cm}^{2}\right)$. An aqueous suspension of the catalyst under study was prepared by ultrasonically dispersing it in ultrapure water (Milli-Q) and Nafion. An aliquot of the well-dispersed suspension was pipetted on the pyrolitic carbon disk substrate surface and dried at $80^{\circ} \mathrm{C}$ under nitrogen atmosphere, resulting in a platinum loading of $0.1 \mathrm{mg} \mathrm{cm}^{-2}$ (33 wt\% Nafion). After preparation, the electrode was immersed into the deaerated $0.5 \mathrm{M} \mathrm{H}_{2} \mathrm{SO}_{4}$ electrolyte, prepared from high purity reagents (Merck) and water purified in a Milli-Q system. The electrolyte was saturated with pure $\mathrm{N}_{2}$ or CO gases (99.997\%, Air Liquide), depending on the experiments.

For the electrochemical characterization, cyclic voltammograms were recorded in the electrolyte solution $\left(0.5 \mathrm{M} \mathrm{H}_{2} \mathrm{SO}_{4}\right)$ between $0.05 \mathrm{~V}$ and $0.85 \mathrm{~V}$ vs. RHE at a scan rate of $0.02 \mathrm{~V} \mathrm{~s}^{-1}$. CO stripping voltammograms were obtained after bubbling this gas in the cell for $10 \mathrm{~min}$ at $0.2 \mathrm{~V}$ vs. RHE, followed by nitrogen purging to remove the excess 
1 of $\mathrm{CO}$. The admission potential was selected considering that for this value maximum

2 adsorbate coverage is achieved for $\mathrm{CO}$ adsorption [40]. Electrochemical surface active 3 areas were determined from the integration of the $\mathrm{CO}$ oxidation region $(0.45-0.85 \mathrm{~V}$ vs. 4 RHE), after correction for double layer capacitance, and assuming $420 \mu \mathrm{C} \mathrm{cm}{ }^{-2}$ 5 involved in the process. Methanol electrochemical oxidation reaction was studied by 6 linear sweep voltammetry, with a scan rate of $0.005 \mathrm{~V} \mathrm{~s}^{-1}$, substituting the base 7 electrolyte for a deaerated solution of methanol $(2 \mathrm{M})$ in the base electrolyte $(0.5 \mathrm{M}$ $\left.8 \mathrm{H}_{2} \mathrm{SO}_{4}\right)$. 


\section{Results and discussion}

Main textural differences between the two pristine CNFs are the higher surface area and the higher pore volume of CNF600, this is, the CNF characterized by a relatively low synthesis temperature $\left(600^{\circ} \mathrm{C}\right)$, as summarized in Table 1 . Despite its lower surface area, CNF700 (synthesized at $700^{\circ} \mathrm{C}$ ) has shown a better performance than CNF600 when used as PtRu support [41], because of the influence of support graphitization degree, which leads to an enhanced metal-support interaction. Consequently, we have included both supports, CNF600 and CNF700, with high and low surface area, respectively.

Notice that the treatment of CNFs with nitric acid at $110{ }^{\circ} \mathrm{C}$ (named ' $\mathrm{N}$ ') and with nitric and sulfuric acids at room temperature (named 'NS') leads to the same oxygen content: $4.9 \mathrm{wt} \%$ for oxidized CNF600 and $2.8 \mathrm{wt} \%$ for oxidized CNF700. Similar oxygen contents will allow the comparison of supports and individuation of the influence of other parameters on the catalytic performance, e.g. the surface chemical composition or the textural properties. In general terms, both the surface area and the pore volume increase after these oxidation treatments, prompt by the roughening of the surface and the removal of nickel traces [34]. The oxygen content is clearly higher for the CNF600 based materials due to the larger surface area. Actually, the surface density of oxygen atoms, calculated taking into account the BET surface areas, indicates an oxygen concentration of about 6-7 atoms $\mathrm{nm}^{-2}$ for the untreated CNFs, which increases to about 10-12 atoms $\mathrm{nm}^{-2}$ after treatment, independently of surface area or type of oxidation process. This increase in oxygen is high enough to make the hydrophobic pristine nanofibers well dispersible in water, as evidenced in Fig 1. To this purpose, CNFs (1 mg) were mixed in a vial containing $\mathrm{n}$-heptane and water, kept under sonication for 1 hour and then the vials were left to settle for 24 hours. The untreated sample presents no affinity with the aqueous phase, remaining mainly in the organic one (upper phase), whereas the treated samples remain well dispersed in the aqueous phase even after 24 hours. This indicates a significant improvement in terms of wettability for the CNFs with both acid treatments.

Fig. 2 shows the composition of the different types of oxygen groups. Temperature programmed desorption (TPD) experiments were carried out to estimate the content in carboxylic acids, anhydrides, lactones, hydroxyl and carbonyl groups 
1 from the desorbed $\mathrm{CO}$ or $\mathrm{CO}_{2}$ at different temperatures, according to previous studies

2 [21, 34]. The treatments of CNFs significantly increase the net content of carboxylic

3 acid $(-\mathrm{COOH})$, lactone $\left(-\mathrm{C}_{2} \mathrm{OOH}\right)$ and carbonyl $(-\mathrm{C}=\mathrm{O})$ groups while decreasing the

4 hydroxyl group (-COH) concentration. Although carbonyl groups are abundant in the

5 pristine CNFs, coming from exposure to air at ambient temperature, they do not seem to

6 favor the wettability of the samples as evidenced in Fig. 1. The significant increase of

7 the concentration of carboxylic acids and lactones explains the better wettability of the

8 oxidized CNFs despite the relatively low increase of surface oxygen concentration.

Table 2 shows some of the main physico-chemical properties of PtRu catalysts supported on the different pristine and oxidized carbon nanofibers. The metal concentration is close to the nominal one in all cases (20 wt \%), as confirmed by EDX and TGA experiments, with an atomic Pt:Ru ratio of approximately 50:50. The maximum catalytic activity for methanol oxidation has been reported to be given by a broad interval of bulk compositions near 40-60 Pt at.\% [42, 43, 44]. In the present work, the variation of this atomic ratio within catalysts (46-52 at.\%) will be considered low enough to influence the electrochemical behavior (at low temperature) in a much lesser extent than the variation of support features.

X-ray diffractograms (Fig. 3) correspond to the face centered cubic (fcc) structure of platinum together with the graphitic carbon reflections. The reflections attributed to metal particles are slightly shifted towards higher angles than the corresponding supported Pt (lattice parameter of $0.392 \mathrm{~nm}$ for Pt supported on carbon), as a result of the alloy with ruthenium. This is also evidenced by the lattice parameter, calculated from the Bragg equation (Table 2). The values obtained are lower than that of pure platinum supported on carbon nanofibers (ca. $0.392 \mathrm{~nm}$ ) [17] and no reflections associated to $\mathrm{Ru}$, or metal oxides are present, indicating that $\mathrm{Ru}$ is alloyed to the platinum structure. A high degree of alloy has demonstrated to offer a better catalytic activity in PtRu catalysts supported on carbon nanofibers [45].

PtRu crystal sizes, calculated from the broadening of the (220) reflection and applying the Scherrer's equation, were found between 1.8 and $2.3 \mathrm{~nm}$. With the treatment labeled as NS, there is a slight increment in crystal size of PtRu alloys, not observed for the support treated with nitric acid alone. Taking into account that PtRu nanoparticles have been obtained by the microemulsion procedure, an increase of 
1 particle size is attributable to a certain agglomeration of nanodroplets on the surface of

2 CNFs. As this phenomenon is not observed with CNF treated with nitric acid (PtRu

3 particle size is the same as on the untreated based CNF), differences in surface oxygen

4 composition may explain such tendency to agglomerate during either the growth or deposition of metal particles. On the other hand, the carbon related peak (at ca. $26^{\circ}$ ) is more intense and narrow for the CNF700 related catalysts according to the more graphitic character of this support and derivatives compared to CNF600 related ones, maintaining in all cases a high ordering degree.

Theoretical mass surface areas (TMSAs) were calculated from the crystallite sizes determined by XRD analyses and assuming spherical nanoparticles. More details can be found in references $[40,43,46]$. In the present paper, both the particle size and the degree of alloy were considered to derive the TMSA, assuming spherical nanoparticles and correcting for the value of density. It is remarkable that high theoretical values up to $207 \mathrm{~m}^{2} \mathrm{~g}^{-1}$ are obtained, which highlights the importance of synthesizing small PtRu nanoparticles to maximize the noble metal utilization.

Regarding the electrochemical characterization, Fig. 4 shows the response in the oxidation of a $\mathrm{CO}$ monolayer, adsorbed at $0.2 \mathrm{~V}$ vs. RHE. The oxidation of CO occurs in a single peak starting at a potential of ca. $0.5 \mathrm{~V}$ vs. RHE. It is well known that the electrochemical oxidation of $\mathrm{CO}$ is a surface structure sensitive reaction [47, 48]. The center of the peak for the catalysts based on pristine CNF600 and CNF700 is indicated with a dashed vertical line. Notice that the oxidation of $\mathrm{CO}$ occurs at slightly more negative potential $(30 \mathrm{mV})$ for the catalysts based on oxidized CNFs (excepting $\mathrm{PtRu} / \mathrm{CNF} 700 \mathrm{NS}$ ). These minimum differences in $\mathrm{CO}$ oxidation potential could be attributed to the variation of surface characteristics, which in turn may derive from differences in particle size or different metal-support interaction. In the case of the treatment with nitric acid the same crystal size was obtained. The better $\mathrm{CO}$ oxidation behavior for PtRu/CNF600N and PtRu/CNF700N with respect to the corresponding untreated supports is consequently attributed to the effect of surface oxygen groups that favor the electrooxidation of $\mathrm{CO}$ at more negative potential values.

The electrochemical surface areas (ECSAs) were calculated from CO stripping curves assuming a charge of $420 \mu \mathrm{C} \mathrm{cm}^{-2}$ in the oxidation of a monolayer of linearly adsorbed $\mathrm{CO}$ normalized by the total amount of metal (PtRu) [48], and the values are 
1 summarized in Table 2. It is remarkable that the catalysts supported on the oxidized

2 CNFs present, in general terms, considerably lower ECSA. This effect is attributed to metal nanoparticles agglomeration on the defects of CNFs. Similar decrease of ECSA was also reported by other authors [26, 49]. They observed a decrease of ECSA between 20 and $50 \%$ with respect to untreated support. It is worth to mention that the effect of the same oxidizing treatment on different CNFs does not result in the same trend with respect to ECSA. Firstly, regarding the treatment based on nitric acid at high temperature $(\mathrm{N})$, the catalyst PtRu/CNF600N presents a ca. 30\% lower ECSA with respect to $\mathrm{PtRu} / \mathrm{CNF} 600$, whereas the catalyst $\mathrm{PtRu} / \mathrm{CNF} 700 \mathrm{~N}$ presents a negligible variation of ECSA with respect to PtRu/CNF700. This means that the presence of carboxylic acid groups on the low surface area CNF700 favors the homogeneous dispersion of $\mathrm{PtRu}$ nanoparticles whereas the same treatment on the high surface CNF600 results in a higher density of defects and consequent lower ECSA [17]. Secondly, regarding the treatment based on nitric and sulfuric acid at room temperature (NS), catalysts are characterized by a slightly higher PtRu particle size, which results in a lower theoretical surface area. This inevitably leads to lower ECSA values with respect to the catalysts based on pristine CNF600 and CNF700.

The electro-oxidation of methanol $\left(2 \mathrm{M} \mathrm{CH} \mathrm{CH}_{3} \mathrm{OH}\right.$ in $\left.0.5 \mathrm{M} \mathrm{H}_{2} \mathrm{SO}_{4}\right)$ was studied at room temperature by linear sweep voltammetry in a half-cell set-up. Fig. 5 includes the polarization curves in terms of mass and specific activity obtained for the PtRu catalysts supported on CNF600-related samples. Two opposite effects are clearly observed when oxidized CNFs are used. Notice that from ECSA determination, lower mass activity should be expected for both CNF600N and CNF600NS supported catalysts since a significant decrease of the number of active sites was found in $\mathrm{CO}$ stripping. In fact, $\mathrm{PtRu} / \mathrm{CNF} 600 \mathrm{~N}$ follows this trend with a $40 \%$ lower current density compared to PtRu/CNF600. However, the catalyst supported on CNF600NS shows a higher current density than CNF600. In this case, the significant increase of intrinsic activity, as evidenced in Fig. 5(b), compensates the decrease of electrochemical surface area. The increased mass activity is due to the higher intrinsic activity for PtRu/CNF600NS, thus, a higher rate of methanol oxidation per catalytic active site. PtRu/CNF600NS presents a higher particle size than PtRu/CNF600 as shown in Table 2. Garcia et al. observed a volcano-shaped curve with a maximum activity in a range of particle size of 1.6-2.2 nm for methanol oxidation at low temperature of highly alloyed PtRu catalysts [46]. 
1 Furthermore, the highest activity obtained for PtRu/CNF600NS is not only explained by

2 the different particle size, but a significant contribution of metal-support interaction

3 influences the catalyst behavior. The two most active PtRu catalysts based on CNF600

4 and CNF600NS were further analyzed by HRTEM, as shown in the representative

5 images of Fig. 6. The images confirm the better distribution of particles and slightly

6 bigger $\mathrm{PtRu}$ particles $(2.3 \mathrm{~nm})$ on the CNF600NS support. Indeed, the ratio

7 ECSA/TMSA, which indicates the efficiency of metal distribution on the surface, is $84 \%$ in PtRu/CNF600NS but $74 \%$ in PtRu/CNF600 due to the presence of fewer agglomerates on the oxidized CNF.

The activity towards the oxidation of methanol for the CNF700-related catalysts is shown in Fig. 7. Notice that both the mass and specific activities of PtRu/CNF700 are higher than that of PtRu/CNF600 (Fig. 5). In a previous work we reported the favorable effect of crystallinity of CNF700 based catalyst when compared to catalysts based on CNFs synthesized at lower temperature [41]. With regard to functionalization, as previously pointed out, oxidation of CNFs results in different trends depending on the properties of the original carbon material. In the case of highly graphitic CNF700, the oxidation with nitric and sulfuric acid leads to a dramatic decrease of both mass and specific activity. This is in accordance with the $\mathrm{CO}$ oxidation shift to more positive potential of $80 \mathrm{mV}$ (Fig. 4), which accompanied by a significant decrease of ECSA (40\% lower), results in a poor activity for the electro-oxidation of methanol. On the other hand, the oxidation with nitric acid $(\mathrm{PtRu} / \mathrm{CNF} 700 \mathrm{~N})$ results in a better activity (both mass and specific) in the high current density region. This region is controlled by the diffusion of methanol to the active sites. As PtRu/CNF700 and PtRu/CNF700N present similar features, the better wettability of CNF700N may favor the oxidation at high current demand, where it is envisaged an improved accessibility of methanol to the active sites. The two best catalysts based on highly graphitic CNF700 were also analyzed by HRTEM, as shown in the representative images of Fig. 8. In this case, no significant differences were encountered within the catalysts structure and distribution of PtRu nanoparticles, confirming the physico-chemical properties analyzed in the previous discussion.

The effect of oxidizing CNFs is strongly related to their properties. High surface area CNF600 behaves like the well-studied carbon blacks [24-26, 30, 31]. A detrimental effect on the electrochemically active surface area comes with support oxidation. This is 
1 only compensated by the presence of certain oxygen functionalities like lactones or

2 carbonyl whereas hydroxyl or carboxylic acid groups seem to hinder metal-support 3 interaction. On the other hand, highly graphitic carbon nanofibers present a good 4 catalytic activity with no necessary oxidizing treatment. Only at high current density, 5 where the diffusion of methanol is more hindered, the enhancement of surface polarity 6 might aid to obtain up to $20 \%$ higher activity.

7 


\section{Conclusions}

Highly graphitic carbon nanofibers have been oxidized by two different acid treatments and studied as PtRu supports. Pristine CNFs are characterized by different surface areas (87 and $143 \mathrm{~m}^{2} \mathrm{~g}^{-1}$ ) derived from the synthesis at two distinct temperatures. Acid treatments are effective to introduce oxygen groups. These produce hydrophilic CNFs with similar surface oxygen content of $2.8 \mathrm{wt} \%$ for the low surface CNF (CNF700) and 4.9 wt\% for the high surface CNF (CNF600). Moreover with the oxidation both surface area and pore volume increase.

The microemulsion route used to synthesize PtRu nanoparticles leads to a particle size of about $2 \mathrm{~nm}$. The CO electro-oxidation occurs at slightly more negative potential on the PtRu catalysts based on oxidized CNFs, which evidences a better metalsupport interaction. The latter results in an improved catalytic activity toward the methanol electro-oxidation as evidenced from the polarization curves. Nonetheless, the effect of oxidation treatments is not independent of the CNF properties, which is a key parameter for a convenient support optimization. The optimum oxidized CNF support is thus obtained when balancing three factors: a sufficient electrochemical surface area, an improved metal-support interaction due to the effect of oxygen functionalities, and a better methanol diffusion through the catalyst pores due to the wettability of oxidized CNFs. 


\section{Acknowledgements}

2

7 financial support under the project CTQ2011-28913-C02-01.

8 


\section{References}

[1] Aricò AS, Srinivasan S, Antonucci V. DMFCs: From Fundamental Aspects to Technology Development. Fuel Cells 2001; 1:133-61.

[2] Antolini E. Formation of carbon-supported PtM alloys for low temperature fuel cells: a review. Materials Chemistry and Physics 2003; 78:563-73.

[3] Zhao TS, Chen R, Yang WW, Xu C. Small direct methanol fuel cells with passive supply of reactants. J Power Sources 2009; 191:185-202.

[4] Oliveira VB, Falcão DS, Rangel CM, Pinto AMFR. A comparative study of approaches to direct methanol fuel cells modelling. Int J Hydrogen Energy 2007; $32: 415-24$.

[5] Oliveira VB, Rangel CM, Pinto AMFR. Performance of a direct methanol fuel cell operating close to room temperature. Journal of Fuel Cell Science and Technology 2011; 8:11009-1-8.

[6] Icardi UA, Specchia S, Fontana GJR, Saracco G, Specchia V. Compact direct methanol fuel cells for portable application. J Power Sources 2008; 176:460-7.

[7] Achmad F, Kamarudin SK, Daud WRW, Majlan EH. Passive direct methanol fuel cells for portable electronic devices. Appl Energy 2011; 88:1681-9.

[8] Basri S, Kamarudin SK, Daud WRW, Yaaku Z. Nanocatalyst for direct methanol fuel cell (DMFC). Int J Hydrogen Energy 2010; 35:7957-70.

[9] Jones DJ, Rozière J, Marrony M, Lamy C, Coutanceau C, Léger JM, Hutchinson H, Dupont M. High-temperature DMFC stack operating with non-fluorinated membranes. Fuel Cells Bulletin 2005; 10:12-5.

[10] Peron J, Ruiz E, Jones DJ, Rozière J. Solution sulfonation of a novel polybenzimidazole. A proton electrolyte for fuel cell application. Journal of Membrane Science 2008; 314:247-56.

[11] Sistiaga M, Pierna AR. Application of amorphous materials for fuel cells. Journal of Non-Crystalline Solids 2003; 329:184-7. 
[12] Samant PV, Rangel CM, Romero MH, Fernandes JB, Figueiredo JL. Carbon supports for methanol oxidation catalyst. J Power Sources 2005; 151:79-84.

[13] Antolini E. Carbon supports for low-temperature fuel cell catalysts. Appl Catal, B 2009; 88:1-24.

[14] Siracusano S, Stassi A, Modica E, Baglio V, Aricò AS. Preparation and characterisation of $\mathrm{Ti}$ oxide based catalyst supports for low temperature fuel cells. Int J Hydrogen Energy 2013; 38:11600-8.

[15] Stassi A, Gatto I, Baglio V, Passalacqua E, Aricò AS. Oxide-supported PtCo alloy catalyst for intermediate temperature polymer electrolyte fuel cells. Appl Catal, B 2013; 142-3:15-24.

[16] Zeng J, Francia C, Gerbaldi C, Baglio V, Specchia S, Aricò AS, Spinelli P. Hybrid ordered mesoporous carbons doped with tungsten trioxide as supports for $\mathrm{Pt}$ electrocatalysts for methanol oxidation reaction. Electrochim Acta 2013; 94:80-91.

[17] Sebastián D, Ruiz AG, Suelves I, Moliner R, Lázaro MJ, Baglio V, Stassi A, Aricò AS. Enhanced oxygen reduction activity and durability of Pt catalysts supported on carbon nanofibers. Appl Catal, B 2012; 115-6:269-75.

[18] Tsiouvaras N, Martínez-Huerta MV, Paschos O, Stimming U, Fierro JLG, Peña MA. PtRuMo/C catalysts for direct methanol fuel cells: Effect of the pretreatment on the structural characteristics and methanol electrooxidation. Int $\mathbf{J}$ Hydrogen Energy 2010; 35:11478-88.

[19] Bauer A, Chevallier L, Hui R, Cavaliere S, Zhang J, Jones D, Rozière J. Synthesis and characterization of $\mathrm{Nb}-\mathrm{TiO} 2$ mesoporous microsphere and nanofiber supported Pt catalysts for high temperature PEM fuel cells. Electrochim Acta 2012; 77:1-7.

[20] Guha A, Lu W, Zawodzinski Jr. TA, Schiraldi DA. Surface-modified carbons as platinum catalyst support for PEM fuel cells. Carbon 2007; 45:1506-17.

[21] Figueiredo JL, Pereira MFR, Freitas MMA, Órfão JJM. Modification of the surface chemistry of activated carbons. Carbon 1999; 37:1379-89. 
1 [22] Antonucci PL, Alderucci V, Giordano N, Cocke DL, Kim H. On the role of surface

[23] Yasuda K, Nishimura Y. The deposition of ultrafine platinum particles on carbon black by surface ion exchange-increase in loading amount. Mater Chem Phys 2003; 82:921-8.

[24] Carmo M, Linardi M, Poco JGR. Characterization of nitric acid functionalized carbon black and its evaluation as electrocatalyst support for direct methanol fuel cell applications. Appl Catal, A 2009; 355:132-8.

[25] Carmo M, Brandalise M, Neto AO, Spinacé EV, TaylorAD, Linardi M, Poco JGR. Enhanced activity observed for sulfuric acid and chlorosulfuric acid functionalized carbon black as PtRu and PtSn electrocatalyst support for DMFC and DEFC applications. Int J Hydrogen Energy 2011; 36:14659-67.

[26] Salgado JRC, Paganin VA, Gonzalez ER, Montemor MF, Tacchini I, Ansón A, Salvador MA, Ferreira P, Figueiredo FML, Ferreira MGS. Characterization and performance evaluation of $\mathrm{Pt}-\mathrm{Ru}$ electrocatalysts supported on different carbon materials for direct methanol fuel cells. Int J Hydrogen Energy 2013; 38:910-20.

[27] Figueiredo JL, Pereira MFR. Synthesis and functionalization of carbon xerogels to be used as supports for fuel cell catalysts. J Energy Chem 2013; 22:195-201.

[28] Alegre C, Gálvez ME, Baquedano E, Moliner R, Pastor E, Lázaro MJ. Oxygenfunctionalized highly mesoporous carbon xerogel based catalysts for direct methanol fuel cell anodes. J Phys Chem C 2013; 117:13045-58.

[29] Alegre C, Gálvez ME, Baquedano E, Pastor E, Moliner R, Lázaro MJ. Influence of support's oxygen functionalization on the activity of Pt/carbon xerogels catalysts for methanol electro-oxidation. Int J Hydrogen Energy 2012; 37:7180-91.

[30] Gómez de la Fuente JL, Martínez-Huerta MV, Rojas S, Terreros P, Fierro JLG, Peña MA. Methanol electrooxidation on PtRu nanoparticles supported on functionalised carbon black. Catal Today 2006; 116:422-32.

[31] Gómez de la Fuente JL, Martínez-Huerta MV, Rojas S, Hernández-Fernández P, Terreros P, Fierro JLG, Peña MA. Tailoring and structure of PtRu nanoparticles 
supported on functionalized carbon for DMFC applications: New evidence of the hydrous ruthenium oxide phase. Appl Catal, B 2009; 88:505-14.

[32] Sebastián D, Ruiz AG, Suelves I, Moliner R, Lázaro MJ. On the importance of the structure in the electrical conductivity of fishbone carbon nanofibers. J Mater Sci $2013 ; 48: 1423-35$.

[33] Sebastián D, Calderón JC, González-Expósito JA, Pastor E, Martínez-Huerta MV, Suelves I, Moliner R, Lázaro MJ. Influence of carbon nanofiber properties as electrocatalyst support on the electrochemical performance for PEM fuel cells. Int $\mathbf{J}$ Hydrogen Energy 2010; 35:9934-42.

[34] Sebastián D, Suelves I, Moliner R, Lázaro MJ. The effect of the functionalization of carbon nanofibers on their electronic conductivity. Carbon 2010; 48:4421-31.

[35] Calvillo L, Lázaro MJ, Suelves I, Echegoyen Y, Bordejé EG, Moliner R. Study of the surface chemistry of modified carbon nanofibers by oxidation treatments in liquid phase. J Nanosci Nanotechnol 2009; 9:4164-9.

[36] Solla-Gullón J, Vidal-Iglesias FJ, Montiel V, Aldaz A. Electrochemical characterization of platinum-ruthenium nanoparticles prepared by water-in-oil microemulsion. Electrochim Acta 2004; 49:5079-88.

[37] Eriksson S, Nylén U, Rojas S, Boutonnet M. Preparation of catalysts from microemulsions and their applications in heterogeneous catalysis. Appl Catal, A 2004; 265:207-19.

[38] Rojas S, García-García FJ, Järas S, Martínez-Huerta MV, Fierro JLG, Boutonnet M. Preparation of carbon supported Pt and PtRu nanoparticles from microemulsion. Electrocatalysts for fuel cell applications. Appl Catal, A 2005; 285:24-35.

[39] Zhou JH, Sui ZJ, Zhu J, Li P, Chen D, Dai YC, Yuan WK. Characterization of surface oxygen complexes on carbon nanofibers by TPD, XPS and FT-IR. Carbon 2007; 45:785-96.

[40] García G, Silva-Chong JA, Guillén-Villafuerte O, Rodríguez JL, González ER, Pastor E. CO tolerant catalysts for PEM fuel cells: Spectroelectrochemical studies. Catal Today 2006; 116:415-21. 
1 [41] Sebastián D, Suelves I, Pastor E, Moliner R, Lázaro MJ. The effect of carbon nanofiber properties as support for PtRu nanoparticles on the electrooxidation of alcohols. Appl Catal, B 2013; 132-3:13-21.

[42] Petrii OA. Pt-Ru electrocatalysts for fuel cells: A representative review. J Solid State Electrochem 2008; 12:609-42.

[43] Aricò AS, Antonucci PL, Modica E, Baglio V, Kim H, Antonucci V. Effect of Pt$\mathrm{Ru}$ alloy composition on high-temperature methanol electro-oxidation. Electrochim Acta 2002; 47:3723-32.

[44] Goodenough JB, Hamnett A, Kennedy BJ, Manoharan R, Weeks SA. Methanol oxidation on unsupported and carbon supported $\mathrm{Pt}+\mathrm{Ru}$ anodes. J Electroanal Chem 1988; 240:133-45.

[45] Lobato J, Cañizares P, Ubeda D, Pinar FJ, Rodrigo MA. Testing PtRu/CNF catalysts for a high temperature polybenzimidazole-based direct ethanol fuel cell. Effect of metal content. Appl Catal, B 2011; 106:174-80.

[46] García G, Baglio V, Stassi A, Pastor E, Antonucci V, Aricò AS. Investigation of $\mathrm{Pt}-\mathrm{Ru}$ nanoparticle catalysts for low temperature methanol electro-oxidation. J Solid State Electrochem 2007; 11:1229-38.

[47] Gasteiger HA, Markovic N, Ross PN, Cairns EJ. CO electrooxidation on wellcharacterized Pt-Ru alloys. J Phys Chem 1994; 98:617-25.

[48] Green CL, Kucernak A. Determination of the platinum and ruthenium surface areas in platinum-ruthenium alloy electrocatalysts by underpotential deposition of Copper. I. Unsupported catalysts. J Phys Chem B 2002; 106:1036-47.

[49] Zaragoza-Martín F, Sopeña-Escario D, Morallón E, de Lecea CSM. Pt/carbon nanofibers electrocatalysts for fuel cells. Effect of the support oxidizing treatment. J Power Sources 2007; 171:302-9. 


\section{Captions to figures}

2 Figure 1. Dispersion of CNFs in water and n-heptane, 24 hours after sonication: pristine 3 CNFs (left), CNFs treated with nitric acid (middle) and CNFs treated with nitric and sulfuric acids (right).

5 Figure 2. Oxygen groups concentration estimated by TPD experiments of (a) CNF600 related samples and (b) CNF700 related samples.

7 Figure 3. XRD patterns of the PtRu catalysts supported on pristine and oxidized CNFs.

8 Figure 4. $\mathrm{CO}$ oxidation stripping profiles of the different PtRu catalysts.

9 Figure 5. Polarization curves in the oxidation of $2 \mathrm{M}$ methanol at room temperature of catalysts supported on CNF600 related samples. (a) Mass activity; (b) Specific activity.

12 Figure 6. HRTEM representative images of (a) PtRu/CNF600 and (b) PtRu/CNF600NS.

13 Figure 7. Polarization curves in the oxidation of $2 \mathrm{M}$ methanol at room temperature of catalysts supported on CNF700 related samples. (a) Mass activity; (b) Specific activity.

16 Figure 8. HRTEM representative images of (a) PtRu/CNF700 and (b) PtRu/CNF700N. 
1 Table 1. Properties of the pristine and the oxidized carbon nanofibers.

\begin{tabular}{lcccc}
\hline & $\begin{array}{c}\mathrm{S}_{\mathrm{BET}} \\
\left(\mathrm{m}^{2} \mathrm{~g}^{-1}\right)\end{array}$ & $\begin{array}{c}\text { Pore } \\
\text { volume } \\
\left(\mathrm{cm}^{3} \mathrm{~g}^{-1}\right)\end{array}$ & $\begin{array}{c}\text { Oxygen } \\
\text { content } \\
(\mathrm{wt} \%)\end{array}$ & $\begin{array}{c}\text { Oxygen } \\
\text { atoms } \\
\text { surface } \\
\text { density } \\
\left(\text { at. } \mathrm{nm}^{-2}\right)^{*}\end{array}$ \\
\hline CNF600 & 143 & 0.58 & 2.6 & 6.9 \\
CNF600N & 178 & 0.77 & 4.9 & 10.8 \\
CNF600NS & 158 & 0.70 & 4.9 & 11.7 \\
CNF700 & 87 & 0.30 & 1.5 & 6.4 \\
CNF700N & 93 & 0.29 & 2.8 & 11.2 \\
CNF700NS & 101 & 0.38 & 2.8 & 10.2 \\
\hline
\end{tabular}


1 Table 2. Properties of the PtRu catalysts supported on the pristine and on the oxidized 2 CNFs.

\begin{tabular}{lcccccc}
\hline & $\begin{array}{c}\text { PtRu } \\
\text { concentration } \\
\text { (wt\%) }\end{array}$ & $\begin{array}{c}\text { PtRu } \\
\text { crystal } \\
\text { size }(\mathrm{nm})\end{array}$ & $\begin{array}{c}\text { Pt:Ru } \\
\text { atomic } \\
\text { ratio }\end{array}$ & $\begin{array}{c}\text { Lattice } \\
\text { parameter } \\
(\mathrm{nm})\end{array}$ & $\begin{array}{c}\text { TMSA } \\
\left(\mathrm{m}^{2} \mathrm{~g}^{-1}\right)\end{array}$ & $\begin{array}{c}\text { ECSA } \\
\left(\mathrm{m}^{2} \mathrm{~g}^{-1}\right)\end{array}$ \\
\hline PtRu/CNF600 & 18 & 1.8 & $46: 54$ & 0.387 & 192 & 142 \\
PtRu/CNF600N & 23 & 1.8 & $52: 48$ & 0.385 & 207 & 103 \\
PtRu/CNF600NS & 18 & 2.3 & $47: 53$ & 0.389 & 132 & 111 \\
PtRu/CNF700 & 21 & 1.9 & $47: 53$ & 0.388 & 172 & 113 \\
PtRu/CNF700N & 23 & 1.9 & $46: 54$ & 0.387 & 191 & 115 \\
PtRu/CNF700NS & 21 & 2.2 & $50: 50$ & 0.389 & 145 & 67 \\
\hline
\end{tabular}

3 TMSA: theoretical mass surface area, calculated assuming spherical particles with an average diameter equal to PtRu crystal size and considering the density of the alloy [43, 46].

5 ECSA: electro-chemical surface area, determined by the electrochemical stripping of a CO monolayer.

6

7 
Figure 1
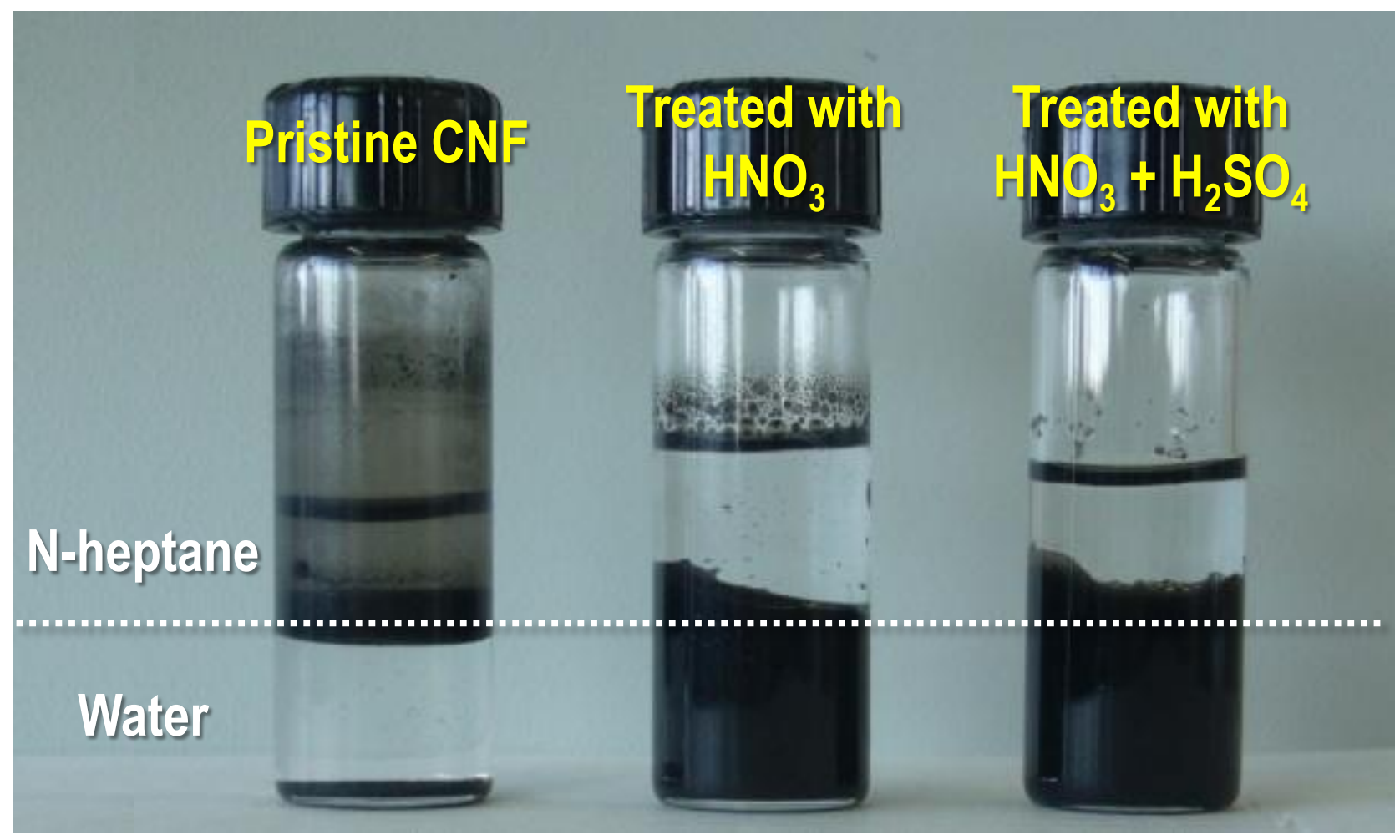

Nheptane

Water 


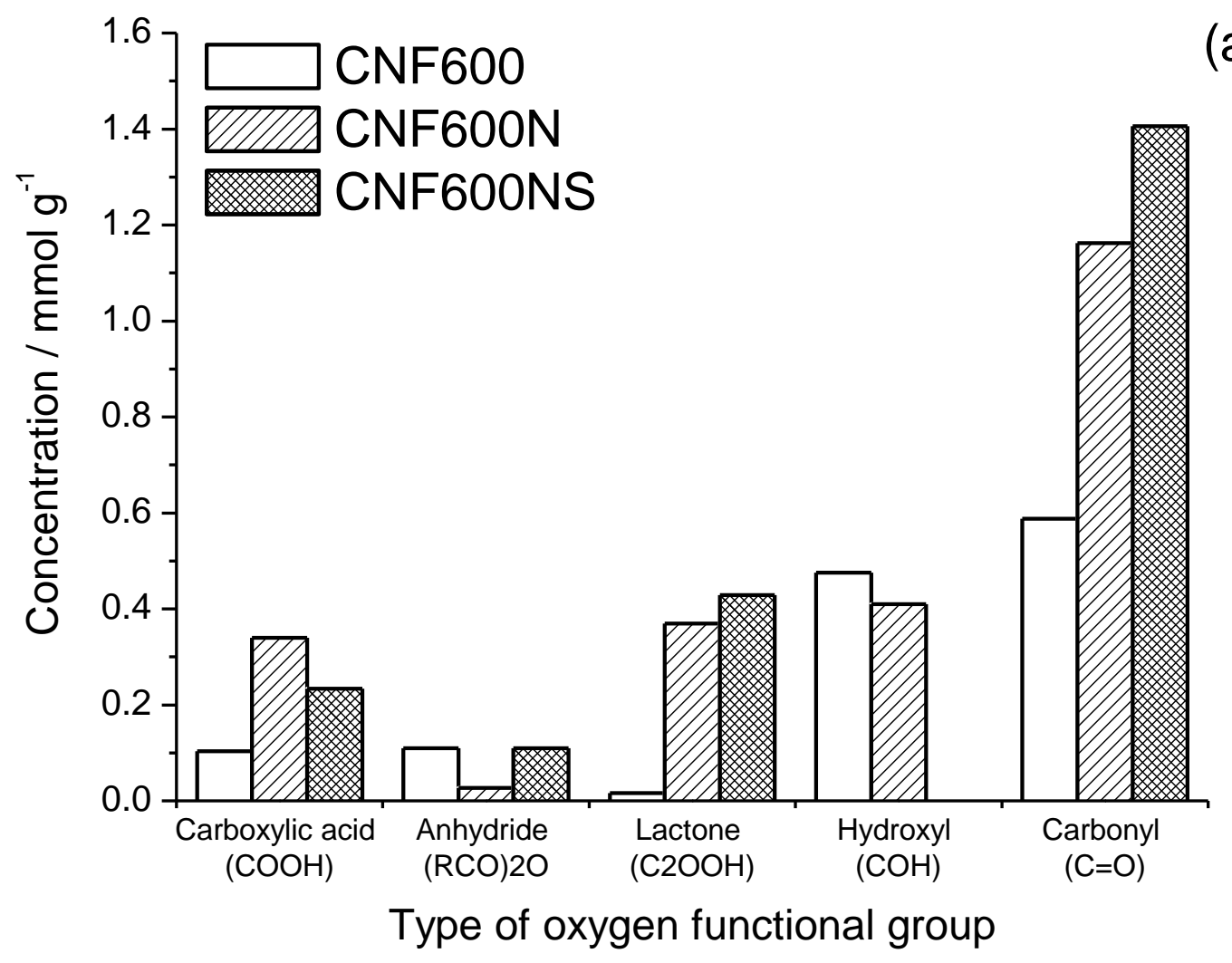

(a)

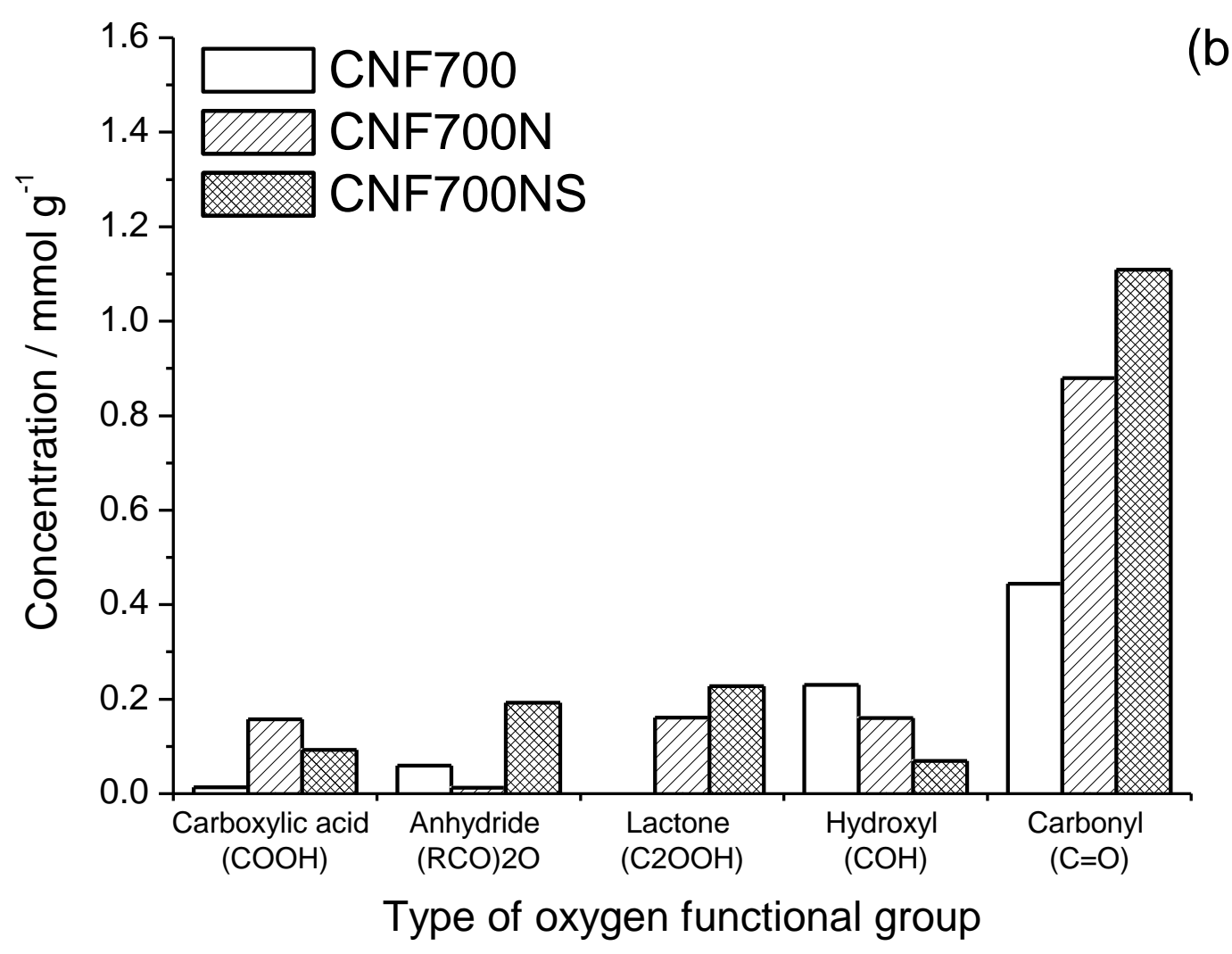

(b) 
Figure 3

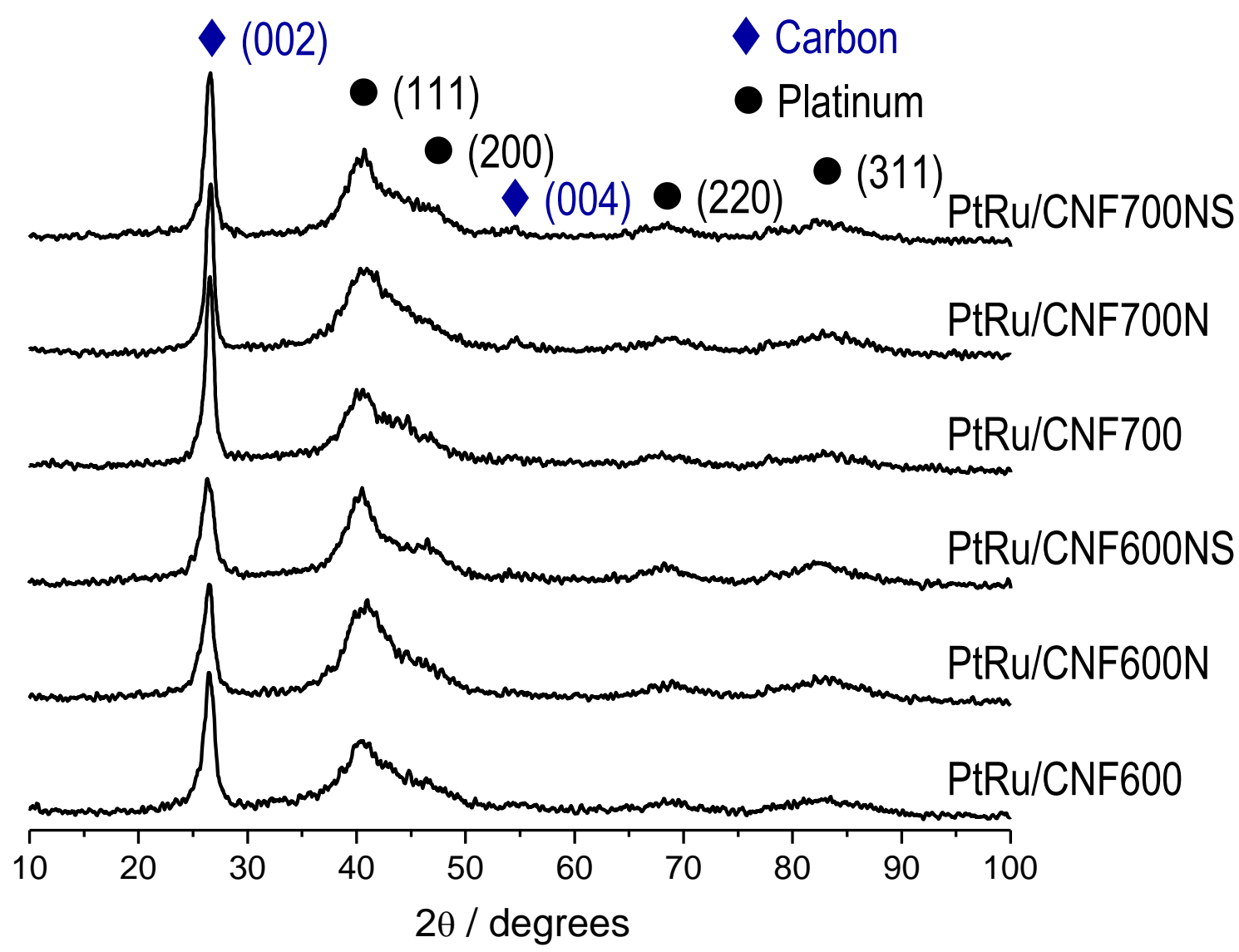


Figure 4

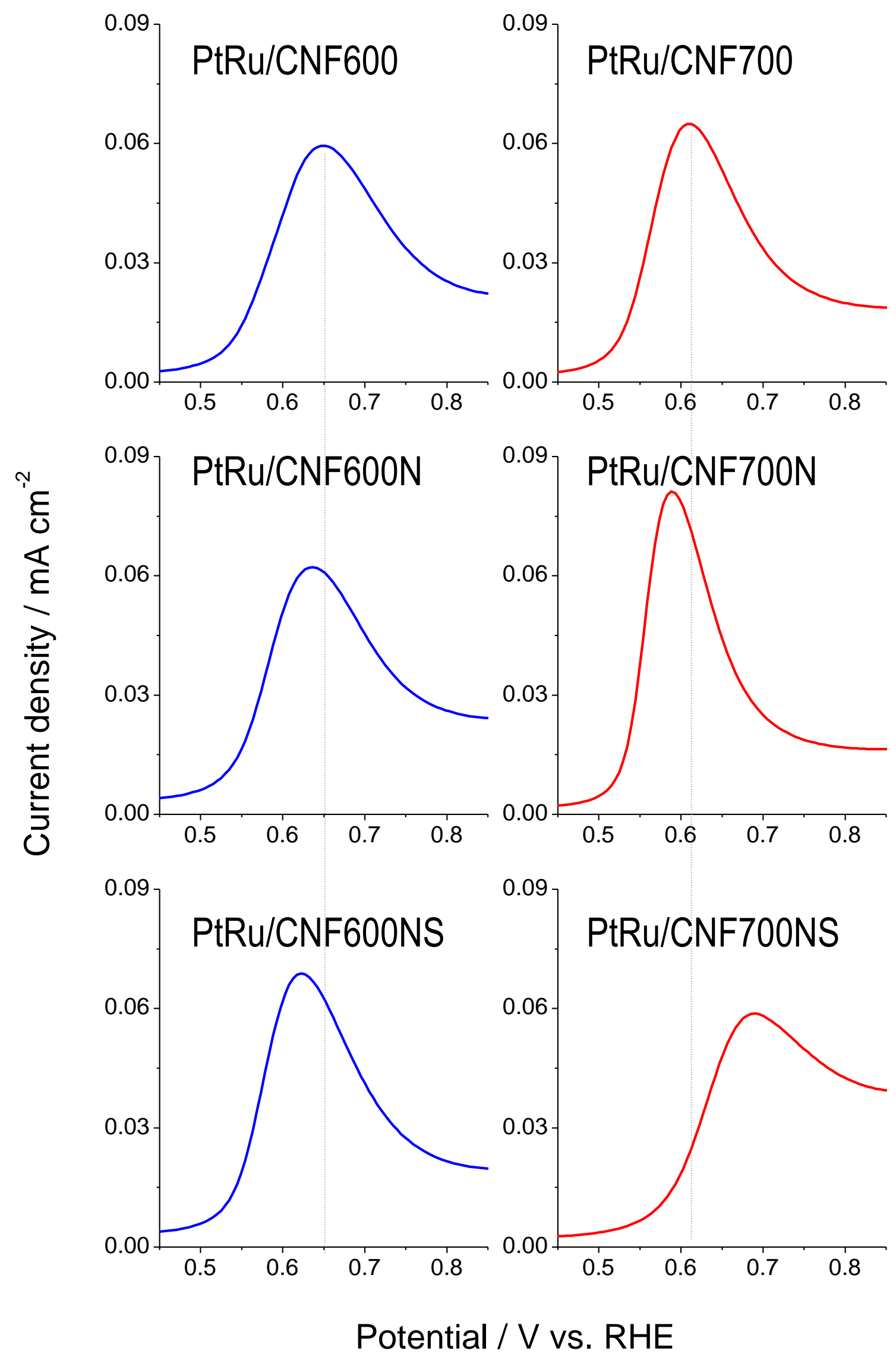




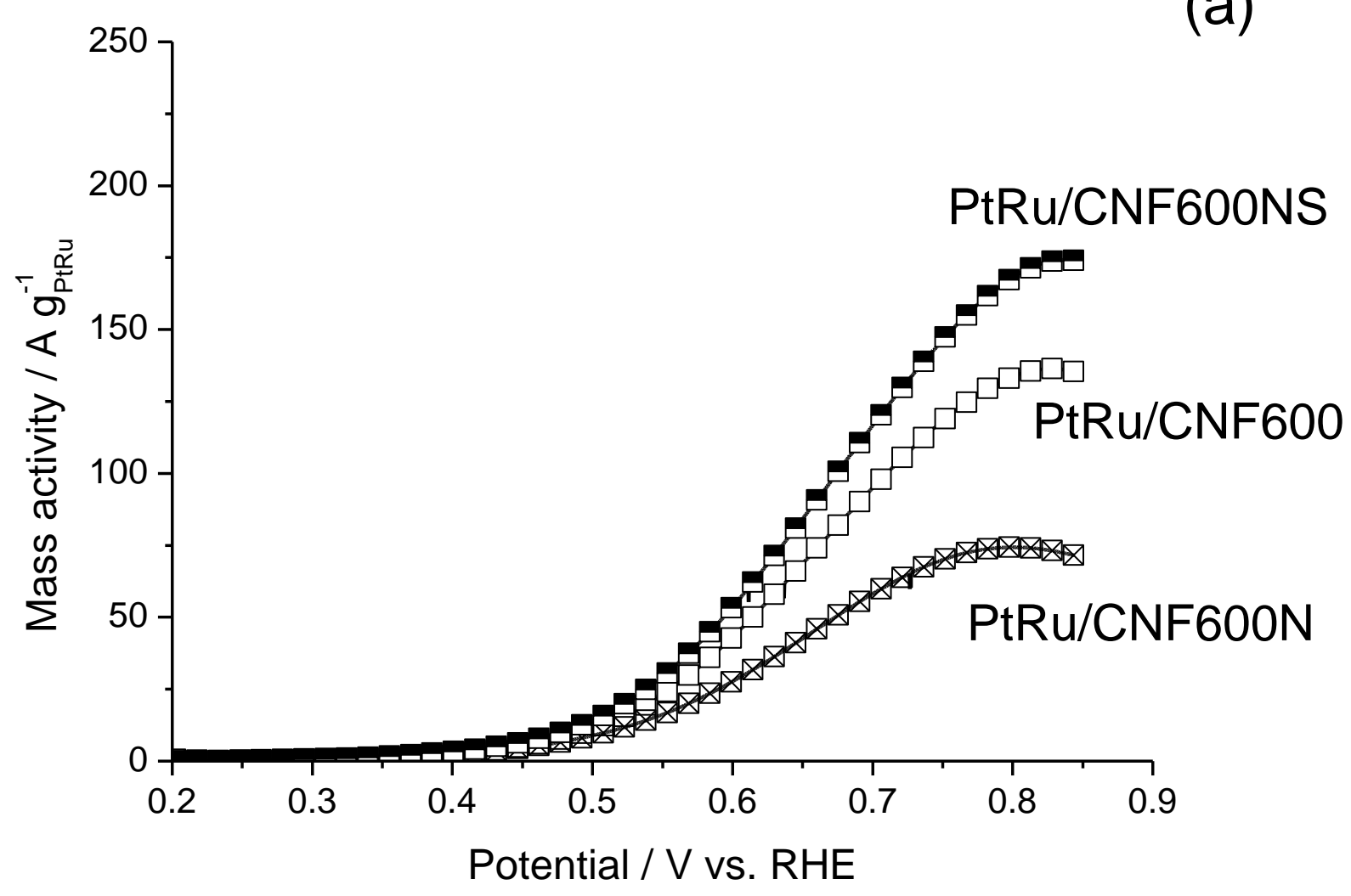

(a)

(b)

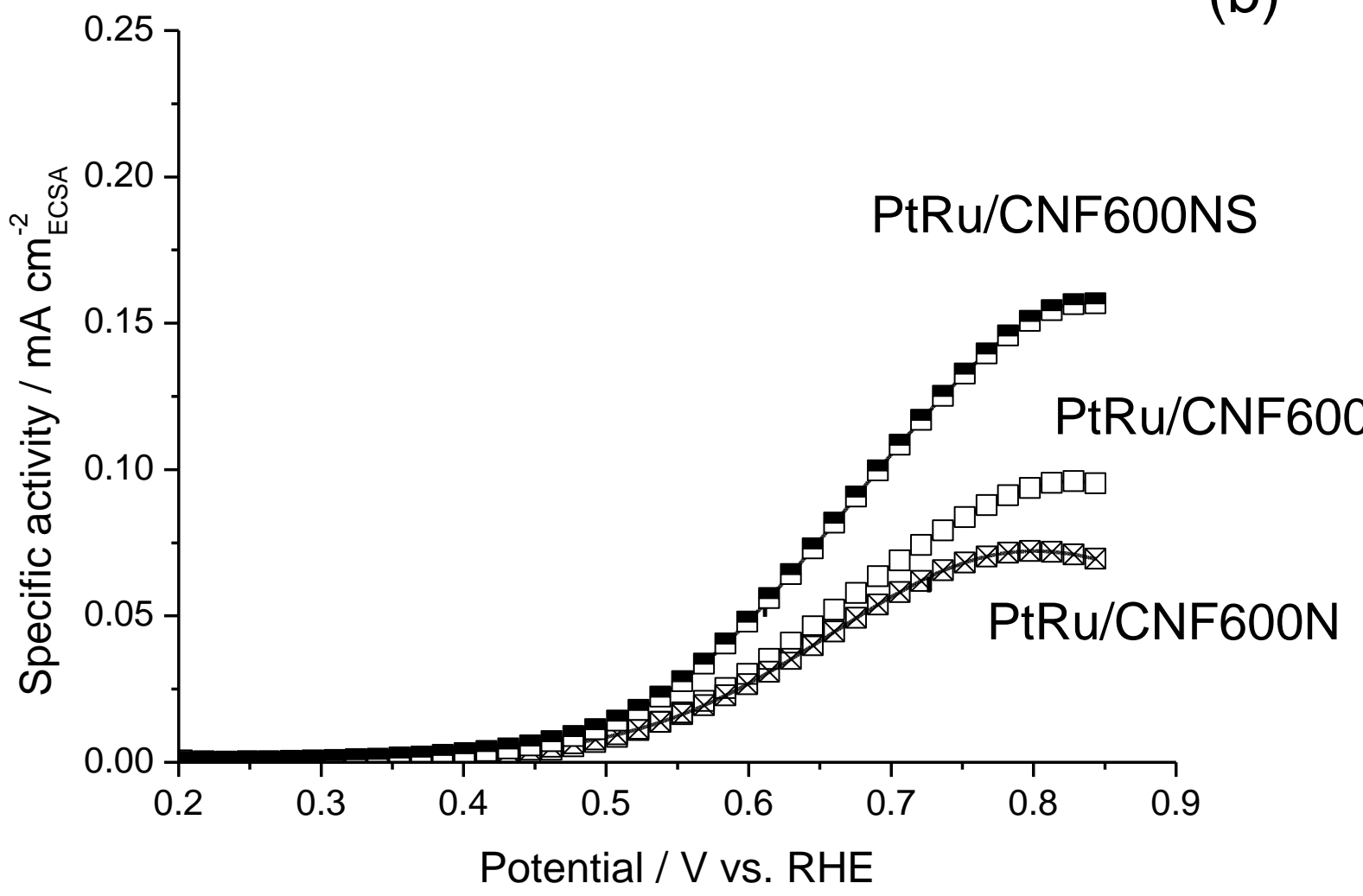




\section{Figure 6}
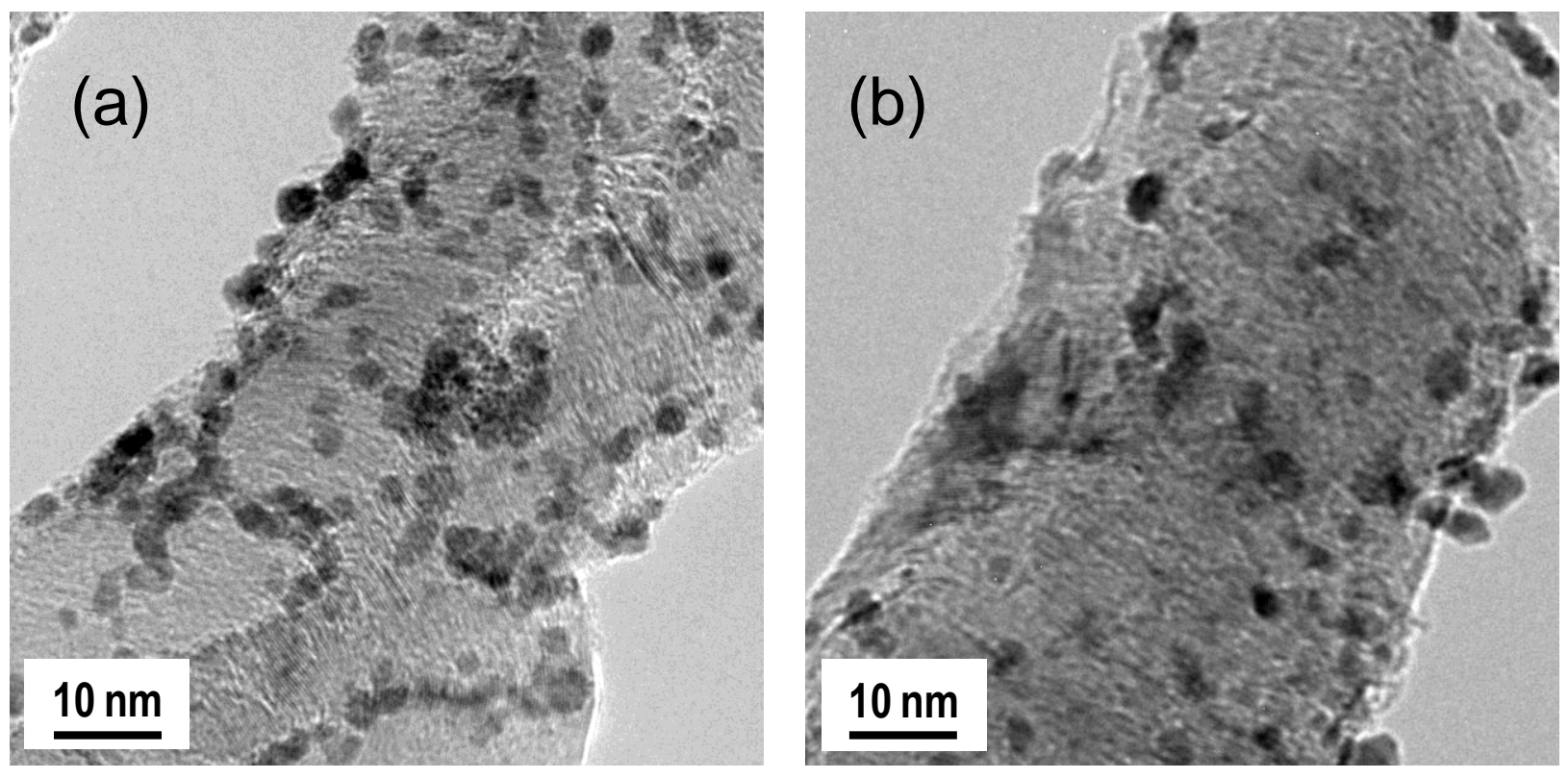
Figure 7

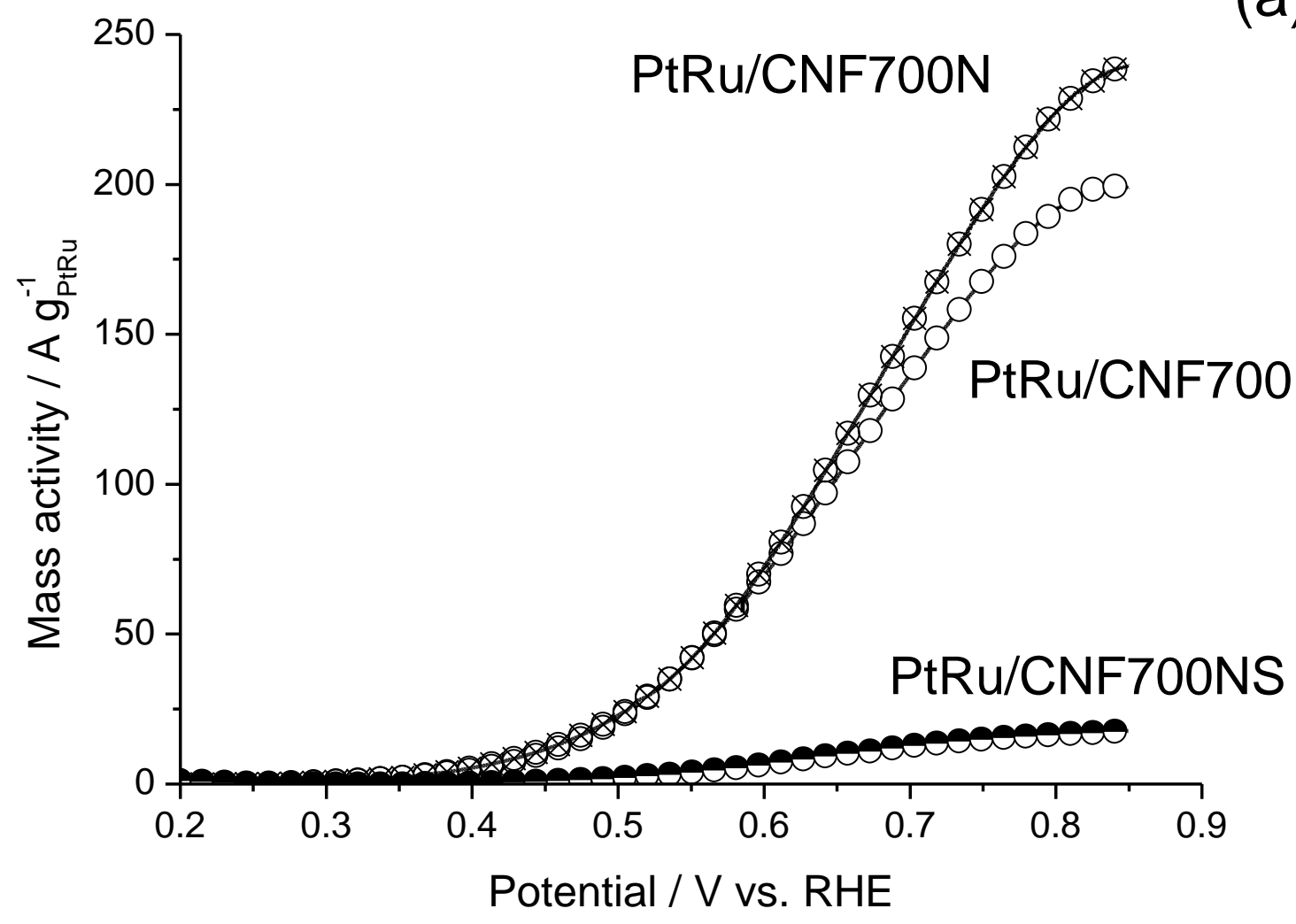

(a)

(b)

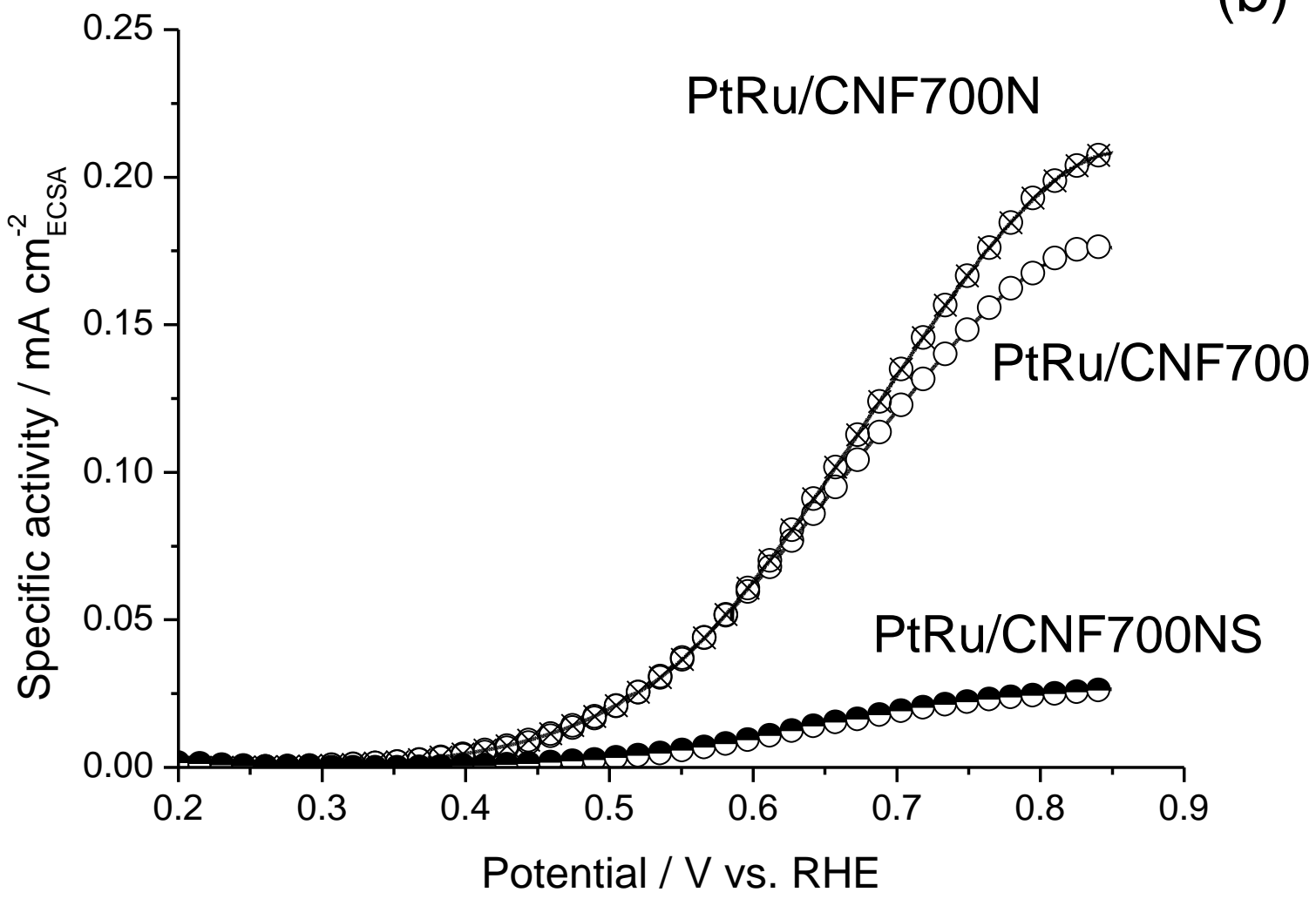




\section{Figure 8}
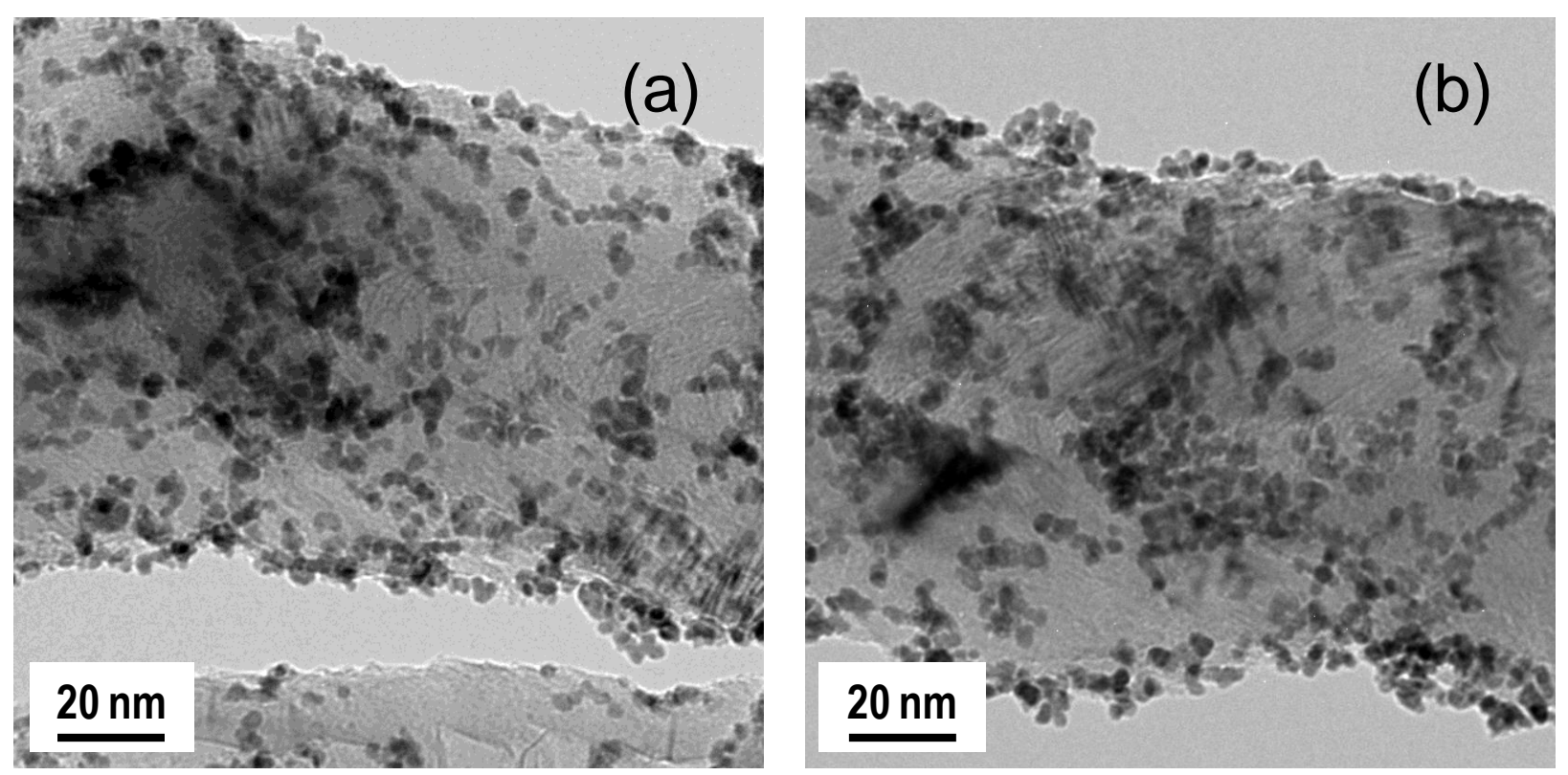